\title{
The Limitations and Application Errors in Multimedia Teaching of College
}

\author{
Zhang Jinping \\ School of Economics \\ Harbin University of Commerce \\ Harbin, China \\ E-mail: nemo080@126.com
}

\author{
Zhang Qiuping \\ School of Economics \\ Harbin University of Commerce \\ Harbin China \\ E-mail: iamsophyzhang@163.com
}

\begin{abstract}
On the basis of analysis on the limitations of multimedia teaching modes This paper points out that there are application errors in the teaching management for some departments in the university, they also exists in multimedia teaching technology.
\end{abstract}

Keywords-multimedia technology; classroom teaching; teaching effect

\section{INTRODUCTION}

In order to improve the teaching effect, many universities take the multimedia teaching which is brought into the classrooms as a kind of advanced teaching methods, and take the corresponding incentive measures to encourage teachers to use multimedia teaching. Compared with traditional teaching method, the multimedia teaching has its own advantages. But the multimedia teaching is not suitable for all courses and multimedia teaching in the lesson is a worthy disputing problem.

According to the teaching experience and feedback information of students with many years, and the advantages and limitations that the multimedia itself owns, this paper analyzes two modes adopted by many universities, those are "teacher's explanation + multimedia courseware show" and "teacher's explanation + multimedia courseware show + the blackboard inference”. Some limitations and multimedia teaching technology application errors will be studied deeply, which can make reform of using multimedia teaching improve the teaching effect to the real purpose.

\section{THE LIMITATIONS OF THE MULTIMEDIA TEACHING}

Although the multimedia teaching technology is applied to the classroom teaching, which can improve the efficiency of classroom teaching and make the classroom teaching more attractive, the multimedia teaching is also a doubleedged sword whose limitations can't be ignore.

\section{A. The Limitations of "teacher's explanation + multimedia courseware show"}

The teaching mode as "teacher's explanation + multimedia courseware show" is made in advance with multimedia courseware which can substitute the blackboard in the traditional classroom teaching mode. This mode is a kind of update in teaching tools.

1)To make the multimedia teaching to improve the teaching effect, we must display the advantages of the multimedia teaching technology compared with the traditional teaching tools, such as the advantages of dynamic image, more prominent auditory and visual effects, etc. Therefore, the classroom teaching mode requires that teachers master the technology of making multimedia courseware combining course features, which will be more attractive no matter from the vision, or from the content.

2)Making the Teacher Marginalized in the Classroom Teaching. The common defect in the multimedia courseware and the blackboard is the single flow of information. There is no feedback mechanism, which makes that teachers can't accept students' feedback. The two-way flow of information between the teachers and students means that the teacher is not only the submitter of the information, but also the receiver of the students' feedback information. Then the teacher can make adjustment timely and solve students' questions according to students' feedback on teaching information. So the teacher is the important source for educational communication channel. In the teaching mode of "teacher's explanation + multimedia courseware show" , the multimedia courseware becomes the focus for teachers and students, and the teacher is marginalized, thus should be in the leading position in teaching.

3)Rich Expression without Thinking Process. Learning is a process of wisdom accumulation and ability training. But for the college courses and the speculative courses with basic theory, it is more important for the teacher to give students knowledge besides the conclusion. The process of knowledge inference and interpretation for the teacher is not a simple process of knowledge transfer, but a complicated system with ability training. First of all, students learn to think through observing teacher analysis process, and learn to think from a professional perspective, which can make students undertake independent analysis, judgment and decision-making, and then improve students' contemplative faculties. Secondly, the students observe the problem thinking activity line or track taken by teachers; they can learn to look for the right ideas to solve the problem. Finally, students actively participate in the process of teachers' interpretation and analysis of knowledge; they can get trained on their logical thinking ability which represents the ability to solve problems. The mode of "teacher's explanation + multimedia courseware show" abandons the traditional knowledge carrier that teachers use to inference, but show simple analysis process and conclusion only with 
a multimedia courseware. Thus cannot achieve the purpose of training students'thinking.

4)Improving Instruction Efficiency but Losing Flexibility. Multimedia courseware is made in advance, and it generally can be played in the teaching process. But teachers can scribble the content written on the blackboard according to the students' feedback information timely, and then adjust the train of thought, update relevant content, add and delete some content. At the same time, the classroom teaching can stimulate inspiration for teachers and students mutually, and the blackboard is indispensable props for interaction mechanism. For instance, in problem conductive teaching, the teachers will list the questions and ideas on the blackboard, and then guide the students to think and discuss. And then the students' ideas and questions are listed on the blackboard, discussed by the teachers and students, possible conclusion can be inducted at last. In the mode of "teacher's explanation + multimedia courseware show", due to the lack of the blackboard, this content can be displayed only through the language. That means there is only one channel for information transmission, which is very drab, and it cannot put the content in a picture to explain, analyze and discuss. In addition, in the process of the explanation, the writing by the teacher is also the process of noting but thinking for the students. But the rapid play of multimedia courseware and interpretation by the teachers will leave no time for the students to think and digest what the teachers explain.

In view of the limitation for the mode of "teacher's explanation + multimedia courseware show", this generally applied to academic report. Because the academic report is a research report, which has no obligation to stimulate students' interest in learning, training students' ability to think. But those are the basic responsibility for the classroom teaching.

\section{B. Limitations in the Mode of “Teacher's explanation +} multimedia courseware show + the blackboard inference"

The mode of "Teacher's explanation + multimedia courseware show + the blackboard inference" is the organic combination of the modern teaching techniques and traditional teaching tools, which retains traditional teaching tool such as the blackboard, and increases the multimedia. Those two with teachers together form the three main bodies to transfer information to the students.

1)Teaching information will be lost. In the multimedia classroom, the computer operating platform and multimedia screen is commonly set by the each side the classroom platform. Teachers need to go to the operation platform to turn the page at any time, and even the teachers stand after computer operation platform all the time. If the students make multimedia screen as main body to receive teaching information, the teacher will be often free out of the students' visual pictures, or not in the students' visual images, so the teacher's explanation becomes a voiceover. The students cannot receive information transferred by the teachers' eyes, face and body language. Some research shows that $80 \%$ of the information is not transferred by language. If students take with the teachers as the main body of receiving information, it will weaken the function of multimedia information. In addition, if the content that the teacher interprets is completely consistent with the multimedia, students usually search the content that the teachers explain in multimedia screen, because visual identity and memory effect higher than hearing. But it would waste time, and at the same time, there is also a phenomenon that what the students actually see is not synchronous with the content that the teachers explain.

2)Scattering the students' attention. The original intention to encourage utility of the multimedia for teaching is that it can combine auditory and visual, and combine text, images, colors and elegant layout design, which can attract students' attention, stimulate students' interest in their study. But in fact, everything has two sides. The factor that can attract the attention of students also may disperse students' concentration. In the limited time and space, the students are likely to be attracted by beautiful picture, wonderful music, and ignore the teaching information the teacher wants to convey.

3)Adversely matching between the blackboard content and multimedia courseware content affects the teaching effect. The blackboard and multimedia courseware have their own advantages, how to combine both better is a kind of art. There are two extreme cases in using the multimedia courseware and the blackboard: one is that the detailed multimedia courseware is played, meanwhile, some teachers will write the main teaching content on the blackboard again,. The second is that some teachers will be completely dependent on multimedia courseware. The right way should be that the dynamic image shows for the teaching content, a lot of blackboard writing for background material, data, education and discussion topic and so on should be left to the multimedia courseware, then the logical shows and some chart display should be left to the blackboard.

Compared with the first mode, the second mode integrates the advantages of teacher, the blackboard and multimedia courseware, and it should be applied more widely in the teaching.

\section{THE APPLICATION ERRORS IN THE TECHNOLOGY OF MULTIMEDIA TEACHING}

At present, there are still some errors in the multimedia teaching management of the college and the application of the multimedia technology for teachers to finish teaching, which will influence the teaching effect that the multimedia teaching will improve. 


\section{A. Blind Encouraging Multimedia Classroom Teaching}

The multimedia technology and the information for classroom teaching are related by form and content. On the one hand, any content has a certain form, any form is the form of certain content; On the other hand, and the form is decided by the content, the form has the reaction to the content.

1)The multimedia teaching technology is not suitable for all the courses. Course nature and course content determines the form of the transition for teaching information. If you need a lot of image or caption to show teaching content, or large amount of data and complicated charts, or the experiments need showing teach knowledge but without experimental conditions, the multimedia teaching will be better.

2)The multimedia teaching is not necessary in the whole process. Teachers should use the proper technology in the multimedia teaching according to each lecture; otherwise it may produce the effect of the wasted effort. In fact, in the interpretation of knowledge, many methods are available, but for a particular knowledge teaching, the methods are not many. In order to improve the effect of teaching, The teachers need to determine which teaching process the multimedia courseware need be used to display the teaching information, and which should be abandoned.

3)Not all teachers can use multimedia for teaching. Writing on the blackboard and multimedia courseware production and use are necessary skills for all teachers, and they can not replace each other, but with complementary relationship. Therefore, the new teachers in colleges and universities should train their basic skills from the writing on the blackboard, lecture notes and teaching plan writing, and they cann't jump in using the multimedia technology in the classroom teaching.

\section{B. The Process of Multimedia Teaching Is without Supervision and Evaluation on the Effect}

At present, there are some management systems in most colleges to encourage the multimedia teaching. But teaching supervision mechanism on the multimedia teaching has not set up in most of universities.

At present, the common problems for the application of multimedia technology in the college classroom teaching include:

1)When the teachers make multimedia courseware, they will just make original content written on the blackboard or the contents of the textbook moved to the multimedia courseware, and they do not combine with the advantages of multimedia to choose and allocate;

2)When the multimedia courseware is played, continuous full pages will be played. The teachers do not consider whether the students can accept and their feedback on the information.
3)There are much more content on the multimedia courseware page, which will increase the cognitive load of students. The students need to spend time in looking for the corresponding words in the page that the teachers just explain, because of the delay between vision and hearing; it is difficult to deal with both better.

These problem existing in the application of multimedia teaching will be able to cause unnecessary loss of the teaching information. Therefore, the department of teaching management shall make some quality supervision and inspection on the teaching courseware made by the teachers. And they should take spot check on the multimedia teaching, which will ensure that the advanced teaching media will be used to the fullest.

\section{Multimedia classroom layout is not rational, which will influence delivery function of teaching informationt}

The computer operating platform and multimedia screen are set in front of the classroom in the arrangement of the multimedia classroom by some colleges and universities, instead of the original platform and the blackboard. Although the multimedia teaching technology, compared with the relative traditional AIDS is more expressive and stronger in reproduction, the teachers is relatively weak in control of teaching information transition, and the students' participation is also weak. Two spaces should be given to the teachers in the layout of the multimedia classroom: One is the space for the interaction between the teacher and students. The teacher can not sit in front of the computer screen, but stand in front of students to explain. The second is the space for displaying the teaching content. The teacher may leave the content on the blackboard, which makes the students have internal overall view, and refer to the above knowledge when listening to the following content at the same time. Only one page can be displayed by the multimedia each time, which makes the students lack of integrity and continuity on the teaching content.

\section{The Multimedia Technology Is Regarded as a Kind of Means to Reduce Preparing Pressure and Energy Consumption}

Some teachers use the multimedia in the classroom teaching, because they think the multimedia courseware can get "once and for all” result, as long as the repeat classes, the teacher will not write on the blackboard any more. This detail content that should be remembered is written in the multimedia courseware, and then the teachers only need to read out in the classroom, which can save the preparing time. In the multimedia teaching, the teachers can sit in front of the computer to explain what is in the computer screen. It is so easy. In fact, in order to improve the teaching effect, the teachers who use multimedia teaching technology may be more tired. The teachers should prepare lessons according to the different characteristics of different classes and specialties to produce or adjust courseware content. In 
addition to language interpretation and the blackboard inference in the classroom, the multimedia courseware should be also played.

\section{E. The Students Can Copy Multimedia Courseware after Class and They Are Not Required to Take Notes}

The role other information channels play is ignored by the approaches the teachers adopt besides auditory and visual. Only the "listening + looking+ writing + thinking" can achieve the best teaching effect. In fact, the students who attend a lecture with noting think about the content again. Some content in the lectures is not in the courseware, the teachers increase some information according to students' feedback temporarily, which the students record for their thinking and analyzing after class.

\section{CONCLUSION}

Through studies this article draws the following conclusions:

1)The multimedia teaching is a double-edged sword. So appropriate application will ascending teaching effect, but if used undeserved, it will not only influence the transmission of the classroom teaching information, and will distract students' attention, which makes the teachers marginalized in the teaching.

2)The management system for improving the multimedia teaching should be further enhanced, then the systems will make teachers properly use multimedia teaching technology, especially the supervision on new teaching technology application and evaluation will be given.
3)The classroom teaching is not to give the answer to the students, but to guide the students to think, analyze and solve problems. the multimedia teaching technique and teaching are the carriers to transfer teaching information to the students for the teachers. Multimedia courseware can not replace the knowledge inference and problem analysis by the blackboard; it cannot replace the two-way feedback mechanism on the information between the teachers and students.

\section{REFERENCES}

[1] Huan YueQun, Cheng Yaping, Deng Huan. Key Points, Advantages and disadvantages in the Making Multi-media Wares[J]. Moder Education Science and Practice. 2012 (11) : 108-109

[2] Wang Yuanyuan, Shi Kan. Comment on the Negative Cognition on the Multi-media Education in the Middle School[J]. Modern Teaching Science. 2012 (6) : 125-126

[3] Fu Jian. Current Condition and Consideration on the Multi-media Education of the Higher College[J] . Jiangsu Higher Education. 2011 (1) : 88-89

[4] Li Ping, Yuan Qinghai. Consideration on the Multi-media Education taking Information Technology as the case [J] . Heilongjiang Research on the Higher Education. 2005 (12) : 149-150

[5] Qin Fuli. Problem in the Multi-media Education in the Higher College and Countermeasures[J]. Higher Eucation Forum. 2005 (5) : 107-111

[6] Peter J. Rich and Tonya Trip. Ten Essential Questions Educators Should Ask When Using Video Annotation Tools. TechTrends . November/December 2011 Volume 55, Number 6 PP16-24

[7] Jef Peeraer - Peter Van Petegem. Information and communication technology in teacher education in Vietnam: from policy to practice. Educ Res Policy Prac (2012) 11 : 89-103

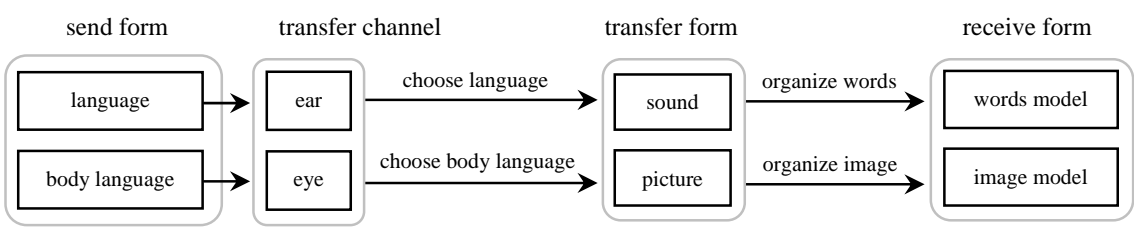

Fig 1 mode of sending and transferring teaching information by the teachers

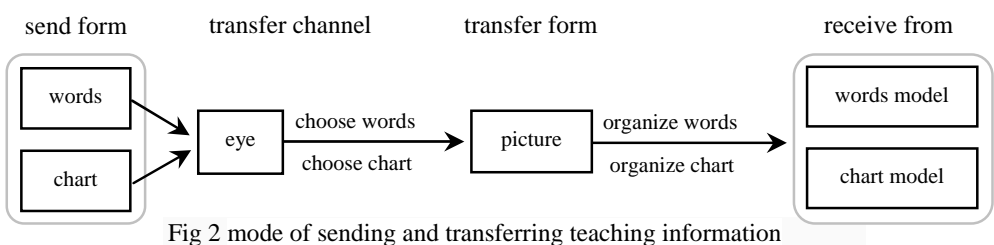

Fig 2 mode of sending and transferring teaching information

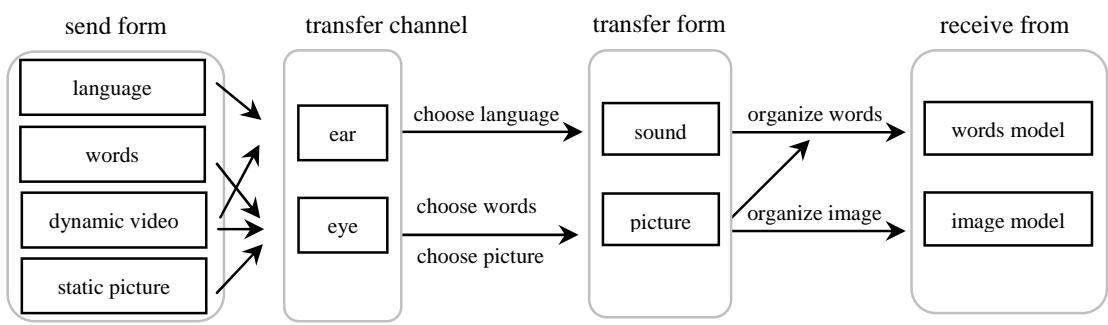

Fig 3 mode of sending and transferring teaching information by the multimedia courseware 